\title{
Investigations on the V(III) Reduction Process of All-Vanadium Redox Flow Battery
}

\author{
Weizao Liu, Dongmei Luo ${ }^{*}$ Fanbo Zeng, Xiaoling Meng, Dan Li \\ College of Chemical Engineering, Sichuan University, Chengdu 610065, China \\ *E-mail: cdhgy@foxmail.com
}

doi: $10.20964 / 110421$

Received: 28 January 2016 / Accepted: 2 March 2016 / Published: 1 April 2016

The V(III) reduction process of all-vanadium redox flow battery was investigated by cyclic voltammetry, polarization curve and AC impedance. It was shown that $\mathrm{V}$ (III)/V(II) couple had undesired electrochemical activity and the V(III) reduction process was in mix controlling step. The probable reason was that the existence of complex of $\mathrm{V}(\mathrm{III})$, which had big ion radius, resulted in large diffusion resistance in the process of mass transfer. Therefore, the kinetics of $\mathrm{V}$ (III) reduction reaction was slow.

Keywords: All-vanadium redox flow battery; Reduction; Electrolyte; Polarization curve; Electrode process

\section{FULL TEXT}

(C) 2016 The Authors. Published by ESG (www.electrochemsci.org). This article is an open access article distributed under the terms and conditions of the Creative Commons Attribution license (http://creativecommons.org/licenses/by/4.0/). 